\title{
Free Radical Scavenging Capacity and Anti-Biofilm Potentiality of Six Wild Edible Fruits from Burkina Faso
}

\author{
Ablassé Rouamba*, Vincent Ouédraogo, Eli compaoré, \\ Moussa Compaoré and Martin Kiendrebeogo
}

Laboratory of Applied Biochemistry and Chemistry (LABIOCA), UFR-SVT, University Ouaga 1 Pr Joseph KI-ZERBO, 03 BP 7021 Ouagadougou 03, Burkina Faso

\author{
*Corresponding author
}

\begin{tabular}{|l|}
\hline Ke y w o r d s \\
Anti-biofilm, \\
$\begin{array}{l}\text { Antimicrobial drug, } \\
\text { Antioxidant, Edible fruit, } \\
\text { Microbial resistance }\end{array}$ \\
\hline Article Info \\
\hline $\begin{array}{l}\text { Accepted: } \\
\text { 16 August } 2018 \\
\text { Available Online: } \\
\text { 10 September } 2018\end{array}$ \\
\hline
\end{tabular}

\section{Introduction}

The development of resistance to antibiotics has become a significant public health problem worldwide as it increases mortality and morbidity due to the reduction of the effectiveness of treatments (Romero et al., 2016). This antibiotic resistance is a consequence of the adaption of infectious pathogens to the types of antimicrobial drugs.
Bacteria use different mechanisms to challenge antimicrobial agents. The formation of biofilms is one of many bacteria defense mechanisms that are responsible for the development of chronic diseases (Nikoli et al., 2014). Biofilm formation shows extreme resistance to the antimicrobial drugs and to the human's defense system (Nogueira et al., 2017). A biofilm is a sessile form of bacterial existence, in which bacteria are covered by a 
matrix containing proteins, nucleic acids and polysaccharides (Packiavathy et al., 2012). Biofilm formation confers to bacteria an extreme resistance resulting in the decrease of the antimicrobials penetration into the deep layers of biofilms and the increase of the bacterial enzymes concentration that become more effective for antibiotics inactivation (Slobodníková et al., 2016).

Bacteria covered by biofilm matrix develop up to 1,000 times more antimicrobial resistance than free-floating (Sánchez et al., 2016). This defense mechanism generates serious consequences for antibiotic therapy and severely complicates treatment options (Ahmad et al., 2014). Regarding to the increase in complexity of most microbial resistance to conventional therapy, it is necessary to develop new strategies to combat microbial resistance. The use of preventive strategy to inhibit bacterial common behavior without killing them is an opportunity promoting to attenuate the pathogenicity of bacteria resistant to available antibiotics. Regarding to the central role of biofilm formation in bacteria resistance development, inhibition of biofilm formation by anti-biofilm agents is an innovative approach.

Research on edible plants as potential sources of new and effective antimicrobials with novel modes of action is interesting to researchers owing their traditionally uses in low income countries to treat numerous infectious diseases. Fruits pulp of Detarium microcarpum, Adansonia digitata, Saba senegalensis, Vittelaria paradoxa, Parkia biglobosa and Ziziphus mauritiana are used in West Africa to treat numerous infectious diseases including dermatitis, dysentery, leucoderma, malaria, tuberculosis and meningitis (Nadembega et al., 2011; Rouamba et al., 2018). This current investigation aimed to evaluate the anti-biofilm potent of fractions from six edible fruit pulp extracts. Furthermore, the free radical scavenging capacity of fractions of fruit extracts was evaluated.

\section{Materials and Methods}

\section{Plants material}

The fresh fruits of wild plants $D$. microcarpum, A. digitata, S. senegalensis, $V$. paradoxa, $P$. biglobosa and $Z$. mauritiana were harvest in Gampela zone situated at 25 $\mathrm{Km}$, east of Ouagadougou (Burkina Faso). Fruits of $V$. paradoxa, P. biglobosa and $S$. senegalensis were collected during June and August lapse period and fruits of $D$. microcarpum, Z. mauritiana and A. digitata during January and March lapse period. The botanical identification of fruits was performed by $\operatorname{Pr}$ Jeanne Millogo of the laboratory of vegetal biology and ecology from the University Ouaga 1 Pr Joseph KIZerbo (Ouagadougou, Burkina Faso). Avoucher herbal were deposited at department herbarium and the following identifications codes were saved: D. microcapum CI: 15928 ; A. digitata CI: 15929; Z. mauritiana CI: 15930; P. biglobosa CI: 15931; V. paradoxa CI: 15932; S. senegalensis CI: 15933.

\section{Bacterial growth}

Pseudomonas aeruginosa PAO1, procured from the Laboratoire de Biotechnologie Végétale (Université Libre de Bruxelles, Gosselies, Belgium) was used to determine the anti-biofilm action of samples. $P$. aeruginosa PAO1 was cultured routinely in Luria-Bertani (LB) broth $\left(37^{\circ} \mathrm{C}\right.$, agitation $\left.175 \mathrm{rpm}\right)$.

\section{Chemicals}

Chemicals were from analytical grade. Silica gel® 60 F254, 60 A was purchased by Merck, Germany. Trolox, 2,2-diphenyl-1picrylhydrazyl (DPPH), ascorbic acid, quercetin, gallic acid, dimethyl sulfoxide (DMSO), deoxyribose, iron sulfate, sodium 
nitroprusside, Griess reagent for nitrite and Luria Bertani (LB) agar were purchased by Sigma-Aldrich (St. Louis, USA). Crystal violet, sodium phosphate dibasic, sodium phosphate monobasic, thiobarbituric acid, Trichloroacetic acid, potassium persulfate, 2,20-azinobis (3-ethylbenzoline-6-sulphonate) (ABTS), acetic acid, salicylic acid, ethanol, methanol, hexane, chloroform and ethyl acetate were purchased by Prolabo (Paris, France).

\section{Extraction and fractionation}

The pulp powder $(25 \mathrm{~g})$ of each fruit was macerated in $250 \mathrm{~mL}$ of ethanol $\left(24 \mathrm{~h}, 25^{\circ} \mathrm{C}\right.$, continuous stirring). Extract was filtrated with a micro pore filter paper and concentrated to dryness in a vacuum evaporator. The ethanol extract of each fruit $(1 \mathrm{~g})$ was adsorbed in $10 \mathrm{~g}$ of silica gel (Silicagel® 60 F254, $60 \AA$ ) and fractioned with hexane, chloroform, ethyl acetate and methanol. Each fraction was evaporated to dryness and solubilized in adequate solvent for the biochemical investigations.

\section{Free radicals scavenging assay}

\section{DPPH radical scavenging assay}

The capacity of each fruit fraction to quench DPPH radical was assessed spectro photometrically at $517 \mathrm{~nm}$ as described by Compaoré et al., (2016). Quercetin was used to plot a standard curve $(\mathrm{y}=-27.94 \mathrm{x}+8.15$; $\mathrm{r} 2>0.99 ; \mathrm{P}<0.0001)$ and data were expressed in mg equivalent of quercetin per 10 gram (mg QE/10g) of extract.

\section{Nitric oxide radical scavenging assay}

The ability of sample to scavenge nitric oxide radical was evaluated at $546 \mathrm{~nm}$ as described previously (Parul et al., 2012). Ascorbic acid was used to generate a calibration curve $(\mathrm{y}=-$
$0.022 \ln x \quad 0.224 ; \mathrm{r} 2>0.99 ; \mathrm{P}<0.0001$ ) and data were expressed in $\mathrm{mg}$ equivalent of ascorbic acid per 10 gram (mg AAE/10g) of extract

\section{Deoxyribose degradation inhibition}

The sample capacity to inhibit the deoxyribose degradation was measured at $532 \mathrm{~nm}$ as described by Perjesi and Rozmer (Perjésiet Rozmer 2011). Gallic acid was used to generate a standard curve $(\mathrm{y}=0.21 \mathrm{x}+37.57$; r2 > 0.99; $\mathrm{P}<0.0001$ 1) and data were expressed in mg equivalent of gallic acid per gram (mg AGE/g) of extract.

\section{ABTS radical quenching assay}

The potentiality of sample to quench the ABTS radical cation was assessed spectro photometrically at $734 \mathrm{~nm}$ following the standard method described by Compaoré et al., (2016). Trolox was used to plot a calibration curve $(\mathrm{y}=-72.38 \mathrm{x}+54.57, \mathrm{r} 2=$ $0.99 ; \mathrm{P}<0.0001$ 1) and data were expressed as mmol trolox equivalent per gram (mmol TE/g) of extract.

\section{Anti-biofilm assay}

The ability of sample to inhibit the $P$. aeruginosa biofilm formation was performed by using the crystal violet assay as described previously (Mutalib et al., 2015). Briefly, 20 $\mu \mathrm{L}$ of each fruit fraction were incubated with $10 \mu \mathrm{L}$ of fresh bacterial suspension in sterile 96 flat wells microtiter plates containing 170 $\mu \mathrm{L}$ of LB broth per well. Following incubation at $37{ }^{\circ} \mathrm{C}$ for $24 \mathrm{~h}$, the bacterial turbidity was measured at $600 \mathrm{~nm}$ to verify any bactericidal action of fruits extracts. For the biofilm assay, content of each well was gently removed and well was washed with $200 \mu \mathrm{L}$ of sterile distilled water to remove non-adherent bacteria. Biofilms formed by adherent cells in plate were fixed with methanol for $15 \mathrm{~min}$ and 
stained with $0.1 \%$ crystal violet for 30 minutes at room temperature. Excess stain was removed and $300 \mu \mathrm{L}$ of acetic acid were added. Optical densities of stained adherent bacteria were measured at $630 \mathrm{~nm}$ using an ELISA microplate reader (BioTek Instruments, USA). Salicylic acid was used as standard and anti-biofilm activity of sample was expressed in percentage of biofilm inhibition.

\section{Data analysis}

All experiments were performed in triplicate $(n=3)$ and data expressed as mean values \pm standard deviation.

Microsoft Excel 2013 was used to generate standard curves and to calculate means and standard deviations. One-way ANOVA followed by Newman Keuls post-test of GraphPad software (GraphPad Software Inc, San Diego, CA, USA) was used to performed statistical analysis. $P$ value $<0.05$ was considered as being significant.

\section{Results and Discussion}

\section{Free radicals scavenging activities}

The potentiality of the plant extracts to quench the free radicals was evaluated by using four antioxidant methods and the data were shown in the table 1. DPPH radical scavenging activities were increasing from $43.68 \pm 1.02$ to $67.51 \pm 0.39 \mathrm{mgQE} / 10 \mathrm{~g}$. The ethyl acetate fraction of $P$. biglobosa and $Z$. mauritiana, and the methanol fraction of $Z$. mauritiana showed the best DPPH radical scavenging activity. However, methanol fraction of $S$. senegalensis showed the best nitric oxide radical scavenging activity (4084.16 \pm 72.86 mgAAE/10g) followed by methanol fraction of Z. mauritiana (3105.00 \pm 92.58 mgAAE/10g). Remarkably, in each plant extract, methanol fractions exhibited more nitric oxide radical quenching activity than the other fractions. Regarding to the inhibition of deoxyribose degradation model, the hexane fraction of $P$. biglobosa, the methanol fraction of $S$. senegalensis and the ethyl acetate fraction of $Z$. mauritiana showed the best antioxidant activity while the best ABTS radical quenching activity was observed with the methanol fraction of $A$. digitata (52.31 \pm $1.71 \mathrm{mmolTE} / \mathrm{g}$ ) followed by the methanol fraction of $Z$. mauritiana $(43.22 \pm 0.85 \mathrm{mmol}$ $\mathrm{TE} / \mathrm{g}$ ).

In general, the methanol and ethyl acetate fractions exhibited the best antioxidant activity. These finding suggested that the antioxidant phytomolecules of the plant extracts were more extractible by polar solvents (methanol and ethyl acetate) than non-polar solvents (chloroform and hexane).

\section{Anti-biofilm activity}

The anti-biofilm effect of fractions of fruit pulp extracts was showed in the table 2 . According to this data, extracts, salicylic acid and vehicle (DMSO $1 \%$ ) showed the similar bacterial turbidity $(P>0.05)$ suggesting that plant extracts and salicylic acid didn't inhibit the bacterial growth. Furthermore, fractions of fruit extracts and salicylic acid reduced significantly the bacterial biofilm formation. The percentage of inhibition of biofilm formation increased from $16.23 \pm 0.60 \%$ to $72.11 \pm 0.20 \%$. The chloroform fraction of $Z$. mauritiana showed the highest anti-biofilm activity. Remarkably, chloroform and methanol fractions exhibited more anti-biofilm activity than ethyl acetate and hexane fractions. All these finding suggested that the ability of fruits extract to inhibit the bacterial biofilm formation would not due to the inhibition of $P$. aeruginosa growth but a plausible disruption and/or an inactivation of biofilms formation. 
Table.1 Free radicals scavenging activity of fruits pulp fractions

\begin{tabular}{|c|c|c|c|c|c|}
\hline Plants & Fractions & $\begin{array}{c}\text { DPPH } \\
(\mathrm{mgQE} / 10 \mathrm{~g})\end{array}$ & $\begin{array}{c}\text { NO'-I } \\
(\mathrm{mgAAE} / 10 \mathrm{~g})\end{array}$ & $\begin{array}{c}\text { DRD-I } \\
\text { (mgGAE/g) }\end{array}$ & $\begin{array}{c}\text { ABTS } \\
\text { mmolTE/g }\end{array}$ \\
\hline \multirow[t]{4}{*}{ A. digitata } & Hex & $52.01 \pm 0.81^{\mathrm{n}}$ & $1.97 \pm 0.14^{\mathrm{p}}$ & $17.45 \pm 2.11^{\mathrm{r}}$ & $32.58 \pm 1.85^{\mathrm{f}}$ \\
\hline & $\mathrm{CHCl}_{3}$ & $60.91 \pm 0.68^{\mathrm{h}}$ & $37.91 \pm 3.72^{\mathrm{i}}$ & $82.78 \pm 1.24^{\mathrm{n}}$ & $18.38 \pm 1.65^{\mathrm{h}}$ \\
\hline & EtAc & $63.74 \pm 0.35^{\mathrm{d}}$ & $19.70 \pm 3.91^{\mathrm{j}}$ & $196.34 \pm 0.94^{b}$ & $35.35 \pm 0.83^{\text {d.c.e }}$ \\
\hline & $\mathrm{MeOH}$ & $63.18 \pm 1.28^{\mathrm{e}}$ & $113.95 \pm 2.46^{\mathrm{g}}$ & $152.00 \pm 1.10^{\mathrm{h}}$ & $52.31 \pm 1.71^{\mathrm{a}}$ \\
\hline \multirow[t]{4}{*}{ D. microcarpum } & Hex & $43.69 \pm 3.88^{\mathrm{p}}$ & Non active & $134.41 \pm 1.09^{j}$ & $42.92 \pm 0.05^{\text {b.c }}$ \\
\hline & $\mathrm{CHCl}_{3}$ & $43.68 \pm 1.02^{\mathrm{p}}$ & $13.81 \pm 0.54^{\mathrm{k} . \mathrm{l}}$ & $158.83 \pm 9.04^{\mathrm{e}}$ & $17.72 \pm 2.79^{\mathrm{h}}$ \\
\hline & EtAc & $62.77 \pm 1.33^{\mathrm{f}}$ & Non active & $35.83 \pm 0.98^{\mathrm{p}}$ & Non active \\
\hline & $\mathrm{MeOH}$ & $66.62 \pm 1.18^{b}$ & $110.01 \pm 3.39^{\mathrm{h}}$ & $170.00 \pm 2.42^{\mathrm{d}}$ & $36.07 \pm 0.97^{\text {d.c }}$ \\
\hline \multirow[t]{4}{*}{ P. biglobosa } & Hex & $54.79 \pm 0.56^{\mathrm{k}}$ & $2.69 \pm 0.12^{\circ}$ & $212.02 \pm 8.70^{\mathrm{a}}$ & $13.80 \pm 2.53^{j}$ \\
\hline & $\mathrm{CHCl}_{3}$ & $50.23 \pm 0.54^{\circ}$ & $280.02 \pm 7.11^{\mathrm{e}}$ & $5.62 \pm 0.98^{\mathrm{s}}$ & $16.48 \pm 1.07^{\text {h.i }}$ \\
\hline & EtAc & $67.51 \pm 0.39^{\mathrm{a}}$ & Non active & $74.40 \pm 1.53^{\circ}$ & $6.33 \pm 0.99^{1}$ \\
\hline & $\mathrm{MeOH}$ & $63.72 \pm 1.31^{\mathrm{d}}$ & $510.27 \pm 7.57^{\mathrm{d}}$ & $146.65 \pm 0.92^{\mathrm{h}}$ & $37.60 \pm 1.36^{\mathrm{d}}$ \\
\hline \multirow[t]{4}{*}{ S. senegalensis } & Hex & $55.38 \pm 0.68^{\mathrm{j}}$ & $0.96 \pm 0.04^{r}$ & $137.85 \pm 0.74^{\mathrm{i}}$ & $41.62 \pm 2.63^{b . c}$ \\
\hline & $\mathrm{CHCl}_{3}$ & $52.37 \pm 0.23^{\mathrm{m}}$ & $1.15 \pm 0.06^{\mathrm{q}}$ & Non active & $34.23 \pm 0.81^{\mathrm{e}}$ \\
\hline & EtAc & $65.92 \pm 1.71^{\mathrm{c}}$ & $118.69 \pm 4.04^{\mathrm{f}}$ & $153.16 \pm 0.89^{\mathrm{g}}$ & $29.14 \pm 1.68^{g}$ \\
\hline & $\mathrm{MeOH}$ & $59.42 \pm 6.59^{i}$ & $4084.16 \pm 72.86^{\mathrm{a}}$ & $210.12 \pm 0.76^{\mathrm{a}}$ & $29.43 \pm 1.63^{\mathrm{g}}$ \\
\hline \multirow[t]{4}{*}{ V.paradoxa } & Hex & $62.22 \pm 1.04^{\mathrm{g}}$ & Non active & $88.51 \pm 2.60^{\mathrm{m}}$ & $9.80 \pm 1.13^{\mathrm{k}}$ \\
\hline & $\mathrm{CHCl}_{3}$ & $52.49 \pm 1.34^{\mathrm{m}}$ & Non active & $116.44 \pm 0.98^{1}$ & $36.06 \pm 2.61^{\text {d.c }}$ \\
\hline & EtAc & $66.43 \pm 0.53^{\mathrm{b}}$ & $14.34 \pm 0.53^{\mathrm{K}}$ & $169.59 \pm 0.40^{d}$ & $39.66 \pm 2.43^{\mathrm{c}}$ \\
\hline & $\mathrm{MeOH}$ & $65.72 \pm 2.75^{\mathrm{c}}$ & $873.93 \pm 10.29^{c}$ & $74.31 \pm 7.85^{\circ}$ & $36.10 \pm 2.11^{\text {d.c }}$ \\
\hline \multirow[t]{4}{*}{ Z. mauritiana } & Hex & $53.19 \pm 5.40^{1}$ & $7.27 \pm 0.24^{\mathrm{m} . \mathrm{n}}$ & $155.45 \pm 2.11^{\mathrm{f}}$ & $13.61 \pm 0.15^{\mathrm{j}}$ \\
\hline & $\mathrm{CHCl}_{3}$ & $59.25 \pm 0.30^{\mathrm{i}}$ & $20.54 \pm 1.27^{\mathrm{j}}$ & $131.73 \pm 1.81^{\mathrm{k}}$ & $29.41 \pm 1.48^{\mathrm{g}}$ \\
\hline & EtAc & $67.36 \pm 0.53^{\mathrm{a}}$ & $7.78 \pm 0.38^{\mathrm{m}}$ & $209.73 \pm 0.60^{a}$ & $37.76 \pm 1.27^{\mathrm{d}}$ \\
\hline & $\mathrm{MeOH}$ & $67.44 \pm 0.39^{\mathrm{a}}$ & $3105.00 \pm 92.58^{b}$ & $192.91 \pm 0.47^{\mathrm{c}}$ & $43.22 \pm 0.85^{b}$ \\
\hline
\end{tabular}

Values are expressed as mean values \pm SD ( $n=6$ independent experiments). Values in each column with different superscripted letters were statistically different $(\mathrm{P}<0.05)$ as determined by using One-Way ANOVA followed by the Newman-Keuls post-test. Hex: Hexane; $\mathrm{CHCl}_{3}$ : Chloroform; EtAc: Ethyl acetate; $\mathrm{MeOH}$ : Methanol; $\mathrm{NO}^{\bullet}-\mathrm{I}$ : Nitric oxide radical inhibition; DRD-I: Deoxyribose degradation inhibition; $\mathrm{mgQE} / \mathrm{g}$ : milligram quercetin equivalent/gram; mgAAE/g: Milligram ascorbic acid equivalent/gram; $\mathrm{mgGAE} / \mathrm{g}$ : milligram gallic acid equivalent/gram, mmolTE/g: millimoltrolox equivalent/gram. 
Table.2 Anti-biofilm activity of fruits fractions

\begin{tabular}{|c|c|c|c|}
\hline Samples & Fractions & $\begin{array}{c}\text { Turbidity (DO } 600 \\
\text { nm) } P>0.05\end{array}$ & $\begin{array}{l}\text { Anti-biofilm activity } \\
(\%)\end{array}$ \\
\hline Vehicle (DMSO $1 \%$ ) & & $0.84 \pm 0.02$ & \\
\hline \multirow[t]{4}{*}{ A. digitata } & Hexane & $0.83 \pm 0.01$ & $16.23 \pm 0.61^{\circ}$ \\
\hline & Chloroform & $0.88 \pm 0.07$ & $31.67 \pm 2.00^{1}$ \\
\hline & Ethyl acetate & $0.76 \pm 0.02$ & $53.33 \pm 0.58^{\mathrm{e}, \mathrm{f}}$ \\
\hline & Methanol & $0.84 \pm 0.01$ & $31.20 \pm 1.63^{1}$ \\
\hline \multirow[t]{4}{*}{ D. microcarpum } & Hexane & $0.90 \pm 0.11$ & $31.63 \pm 0.17^{1}$ \\
\hline & Chloroform & $0.89 \pm 0.02$ & $61.50 \pm 1.38^{\mathrm{b}}$ \\
\hline & Ethyl acetate & $0.88 \pm 0.03$ & $30.91 \pm 1.0^{\mathrm{m}, \mathrm{n}}$ \\
\hline & Methanol & $0.80 \pm 0.07$ & $59.95 \pm 0.54^{c}$ \\
\hline \multirow[t]{4}{*}{ P. biglobosa } & Hexane & $0.83 \pm 0.07$ & $49.92 \pm 1.39^{\mathrm{h}}$ \\
\hline & Chloroform & $0.94 \pm 0.27$ & $54.98 \pm 0.46^{\mathrm{d}}$ \\
\hline & Ethyl acetate & $0.89 \pm 0.02$ & $37.95 \pm 0.52^{\mathrm{k}}$ \\
\hline & Methanol & $0.90 \pm 0.06$ & $55.29 \pm 0.29^{d}$ \\
\hline \multirow[t]{4}{*}{ S. senegalensis } & Hexane & $0.85 \pm 0.01$ & $62.73 \pm 1.89^{b}$ \\
\hline & Chloroform & $0.91 \pm 0.05$ & $52.20 \pm 1.41^{\mathrm{f}}$ \\
\hline & Ethyl acetate & $0.85 \pm 0.02$ & $42.97 \pm 0.23^{j}$ \\
\hline & Methanol & $0.85 \pm 0.04$ & $52.53 \pm 0.43^{\mathrm{t}}$ \\
\hline \multirow[t]{4}{*}{ V. paradoxa } & Hexane & $0.86 \pm 0.02$ & $51.79 \pm 1.13^{\mathrm{f}, \mathrm{g}}$ \\
\hline & Chloroform & $0.84 \pm 0.06$ & $54.26 \pm 1.60^{\mathrm{e}}$ \\
\hline & Ethyl acetate & $0.87 \pm 0.02$ & $48.64 \pm 1.10^{\mathrm{h}}$ \\
\hline & Methanol & $0.86 \pm 0.03$ & $47.04 \pm 1.37^{i}$ \\
\hline \multirow[t]{3}{*}{ Z. mauritiana } & Hexane & $0.83 \pm 0.07$ & $56.25 \pm 1.52^{\mathrm{d}}$ \\
\hline & Chloroform & $0.80 \pm 0.04$ & $72.11 \pm 0.20^{\mathrm{a}}$ \\
\hline & Ethyl acetate & $0.92 \pm 0.02$ & $51.83 \pm 2.11^{\mathrm{t}}$ \\
\hline Standard salicylic acid & Methanol & $\begin{array}{l}0.78 \pm 0.02 \\
0.83 \pm 0.05\end{array}$ & $\begin{array}{c}60.82 \pm 0.54^{4, c} \\
41.07 \pm 0.26\end{array}$ \\
\hline
\end{tabular}

Values are expressed as mean values $\pm \mathrm{SD}$ ( $\mathrm{n}=6$ independent experiments). ${ }^{\mathrm{a}-\mathrm{o}}$ Values with different superscripted letters were statistically different $(\mathrm{P}<0.05)$ as determined by using One-Way ANOVA followed by Newman-Keuls post-test.

Currently, edible fruits have emerged as potential sources of bioactive compounds including antioxidant, antimicrobial, antiinflammatory and anti-cancer compounds (Nile, 2014). More previous investigations on antibacterial plants and their active constituents have been documented but they have focused entirely on planktonic bacteria (Al-sohaibani Murugan, 2012). Studies on properties of plants extract to inhibit bacterial biofilm formation without kill bacteria are less documented. The current investigation highlighted the use of tropical edible fruits as anti-biofilm potent. Data demonstrated that tropical wild edible fruits are potent sources of antimicrobial agents for combatting the microbial resistance. Chloroform and methanol fractions showed in this study more anti-biofilm activity than hexane and ethyl acetate fractions suggesting that fruits extracts contain both polar and non-polar anti-biofilm compounds. Fractions of fruit extracts by 
inhibiting the bacterial biofilm formation could promote new strategies to eradicate infectious diseases caused by antibiotic multiresistant bacteria. Fruit extracts from these medicinal plants may influence biofilm formation mainly by degrading the extracellular matrix, inhibiting peptidoglycan synthesis, efflux pumps and extracellular polymeric substances synthesis, and/or modulating quorum sensing (Nikoli et al., 2014).Fruit extracts could contain backbone compounds that can modify the surface charge of biofilm matrix polymers and thereby inhibiting bacterial adherence (Abdelazizet Aeron, 2014). Lectin present in the bacterial membrane is essential for biofilm formation. Previous studies demonstrated that polysaccharides from antimicrobial plants can inhibit lectin-dependent adhesion of pathogens and biofilm formation (Abdelazizet Aeron, 2014). Fruits pulp of tropical edible fruits was recognized to possess high polysaccharide contents (Cui et al., 2015). Their polysaccharide contents could justify their anti-biofilm activity observed in this study. It has been reported that metal cations such as calcium, magnesium and iron have been implicated in maintaining and in reinforcing biofilm matrix integrity (Abdelazizet Aeron, 2014).

Fruit extracts exhibited in this study free radical scavenging potent that may due to their mono-electronic transfer ability or their ion metal chelating property. Fruit extracts may chelate or reduce metal cations implicated in maintaining matrix integrity and thereby affect the integrity of biofilm matrix. Moreover, the N-acetyl-D-glucosamine-1phosphate acetyl transferase is known as an essential peptidoglycan and lipopolysaccharide precursor in P. aeruginosa pathogens responsible of the biofilm formation and maturation (Riddhi and Liang, 2011). Fruit extracts may inhibit this enzyme leading to biofilm matrix disruption.
This study highlighted the free radical quenching and the anti-biofilm properties of fractions from tropical edible fruits extracts. According to the interesting anti-biofilm activities of fruits used in this study, they constitute potential sources of effective antimicrobial agents for combating microbial resistance. Further phytochemical investigations will involve the isolation and identification of these anti-biofilm compounds.

\section{Competing interest}

The authors declare no competing interests

\section{Authors' contributions}

AR, VO and EC conceptualized the study including sample analysis, compiled and entered the data. MC and MK conceived and designed the experiments. AR drafted the manuscript. All authors read and approved the final manuscript.

\section{Acknowledgment}

The authors gratefully acknowledge the International Foundation for Science (IFS), Stockholm, for supporting the present work under the IFS Grants F/5539-1 and the World Academy of Science (TWAS), Trieste under the grant TWAS 12-044 RG/BIO/AF/AC_G.

\section{References}

Abdel-aziz, S.M.and Aeron, A., 2014. Bacterial biofilm: dispersal and inhibition strategies stages of biofilm development. SAJ Biotechnol., 1 (1):19. doi:10.18875/2375-6713.1.105.

Ahmad, I. Husain, F.M. Maheshwari, M.and Zahim, M., 2014. Medicinal plants and phytocompounds : A potential source of novel medicinal Agents. Antibiofilm 
agents, 8:205-231. doi:10.1007/978-3642-53833-9.

Al-sohaibani, S.and Murugan, K., 2012. Antibiofilm activity of Salvadora persica on cariogenic isolates of Streptococcus mutans : in vitro and molecular docking studies. J Bioadhesion Biofilm Res., 28 (1): 29-38. doi:10.1080/08927014.2011. 647308 .

Compaoré, M. Meda,R.N-T. Bakasso, S. Vlase, L.and Kiendrebeogo, M., 2016. Antioxidant, anti-inflammatory potentials and phytochemical profile of commiphora africana (A. Rich.) Engl. (Burseraceae) and Loeseneriella africana (Wild.) (Celastraceae) stem leaves extracts. Asian Pac J Trop Biomed., 6 (8):665-670.

Cui, T. Lit, X.Y.and Gao, Z.,2015. Determination of polysaccharide contents in chinese fruit by gas chromatography. J Anim Plant Sci., 25 (3):91-95.

Mutalib, L.Y. Nuraddin, S.M. Toma, S. and Aka, H., 2015. Phytochemical screening, antibacterial and antibiofilm evaluation of Lagenaria siceraria fruit growing in Kurdistan Region \Iraq. $J$ Pharmacogn Phytochem., 4 (1):45-49.

Nadembega, P. Issaka, J. Baptiste, J. Poli, F. and Antognoni, F., 2011. Medicinal plants in Baskoure, Kourittenga Province, Burkina Faso: An ethnobotanical study. $J$ Ethnopharmacol., 133 (2): 378-395. doi:10.1016/j.jep.2010.10.010.

Nikoli, M. Vasié, S. Jelena, Đ. Stefanovi, O.and Ljiljana, Č., 2014. Antibacterial and anti-biofilm activity of ginger (Zingiber officinale (Roscoe)) ethanolic extract. Kragujev JSci., 36: 129-136. doi:581.192.582.548.615.33.

Nile, S.H., 2014. Edible berries: Bioactive components and their effect on human health. Nutrition, 30 (2): 134-144. doi:10.1016/j.nut.2013.04.007.
Packiavathy, A.I. Agilandeswari, P. Musthafa, K.S. Pandian, S.K. and Ravi, A.V., 2012. Antibiofilm and quorum sensing inhibitory potential of Cuminum cyminum and its secondary metabolite methyl eugenol against Gram negative bacterial pathogens. Food Res Int., 45(1): 85-92. doi:10.1016/j.foodres.2011.10.022.

Parul, R. Kundu, S.K. and Saha, P., 2012. In vitro nitric oxide scavenging activity of methanol extracts of three Bangladeshi medicinal plants. Pharma Innov., 1 (12):83-88.

Perjési, P. and Rozmer, Z., 2011. Kinetic analysis of some chalcones and synthetic chalcone analogues on the Fenton-reaction initiated deoxyribose degradation assay. Open Med Chem J., 5:61-67.

Riddhi, K. and Liang, J.F., 2011. The activity of small lytic peptide PTP-7 on staphylococcus aureus biofilm. $J$ Microbiol., 49 (4): 663-668. doi:10. 1007/s12275-011-1013-5.

Romero, C.M. Vivacqua, C.G. Abdulhamid, M.B. Baigori, M.D Slanis, A.C. Gaudioso, M.C. and Tereschuk, M.L., 2016. Biofilm inhibition activity of traditional medicinal plants from Northwestern Argentina against native pathogen and environmental microorganisms. Rev Soc Bras Med Trop., $\quad 49$ (6):703-712. doi:10.1590/0037-8682-0452-2016.

Rouamba, A. Compaoré, M.and Kiendrebeogo, M., 2018. Ethnomedicinal Use, Phytochemical constituents and bioactivity of wild edible fruits commonly consumed in Burkina Faso. Asian J. Res. Biochemistry, 2 (3): 1-15 DOI: 10.9734/ AJRB/2018/42781

Sánchez, E. Morales, C.R. Castillo, S. LeosRivas, C. García-Becerra, L. and Martínez, D.M.O., 2016. Antibacterial 
and antibiofilm activity of Methanolic Plant Extracts against Nosocomial Microorganisms. Evidence-Basedd Complement Altern Med., 2016:1-8. doi:10.1155/2016/1572697.

Slobodníková, L. Fialová, S. Rendeková, K.and Ková, J., 2016. Antibiofilm activity of plant polyphenols. Mol Plant
Microbe Interact., 21 (1717): 1-15. doi:10.3390/molecules21121717.

Nogueira, W.J. Costa, R.A. Cunha, M.T. and Cavalcante, T.T.A., 2017. Antibiofilm activity of natural substances derived from plants. African J Microbiol Res., 11 (26):1051-1060. doi:10.5897/AJMR 2016.8180 .

\section{How to cite this article:}

Ablassé Rouamba, Vincent Ouédraogo, Eli compaoré, Moussa Compaoré and Martin Kiendrebeogo. 2018. Free Radical Scavenging Capacity and Anti-Biofilm Potentiality of Six Wild Edible Fruits from Burkina Faso. Int.J.Curr.Microbiol.App.Sci. 7(09): 2085-2093. doi: https://doi.org/10.20546/ijcmas.2018.709.254 